\title{
Entanglement in and ingestion of fishing gear and other marine debris by Florida manatees, 1993 to 2012
}

\author{
Thomas R. Reinert ${ }^{1, *}$, Ann C. Spellman ${ }^{2}$, Brandon L. Bassett ${ }^{3}$ \\ ${ }^{1}$ Florida Fish and Wildlife Conservation Commission, Fish and Wildlife Research Institute, Tequesta Field Laboratory, \\ Tequesta, FL 33469, USA \\ ${ }^{2}$ Florida Fish and Wildlife Conservation Commission, Fish and Wildlife Research Institute, Indian River Field Laboratory, \\ Melbourne, FL 32901, USA \\ ${ }^{3}$ Florida Fish and Wildlife Conservation Commission, Fish and Wildlife Research Institute, \\ Marine Mammal Pathobiology Laboratory, St. Petersburg, FL 33711, USA
}

\begin{abstract}
Entanglement in and ingestion of marine debris by marine life has become a recognized threat worldwide, and the endangered Florida manatee is no exception. Manatees are known to become entangled in various types of fishing gear and other marine debris, and foreign objects are often found in the gastrointestinal tract of dead manatees. We examined a 20 yr dataset (1993 to 2012) of manatee rescue and necropsy records for evidence of entanglement in or ingestion of marine debris. In over 6500 manatee necropsy reports, over $11 \%$ either had ingested or showed evidence of entanglement in marine debris (or both). Fifty manatees died as a direct result of either entanglement in or, most commonly, ingestion of marine debris; fishery-related gear was involved in over $70 \%$ of these cases. With respect to live manatee rescues ( $\mathrm{n}=1244$ ), over $25 \%$ were related to entanglement in or ingestion of fishery gear or marine debris, making entanglement the top anthropogenic reason for rescue during this time. Fishing gear, primarily trap lines and monofilament fishing lines, was a factor in over $85 \%$ of these rescues. Female manatees in particular were disproportionally affected by marine debris. The Florida manatee represents an example of estuarine fauna that is subject to harm from marine debris, and continued efforts to reduce and remove marine debris from estuarine environments will benefit manatees and other estuarine species.
\end{abstract}

KEY WORDS: Marine debris · Florida manatee - Trichechus manatus latirostris · Entanglement • Rescue $\cdot$ Mortality $\cdot$ Fisheries interaction

\section{INTRODUCTION}

Marine debris in the aquatic environment and its impacts on marine life are widespread, both geographically and taxonomically (Laist 1997, Gregory 2009, Gall \& Thompson 2015), becoming such a threat, that the United States Congress passed the 'Marine Debris Research, Prevention, and Reduction Act' (33 USC 1951 et seq.) in 2006, designed specifically to empower the National Oceanographic and

\footnotetext{
*Corresponding author: tom.reinert@myfwc.com
}

Atmospheric Administration and the US Coast Guard to, in part, 'help identify, determine sources of, assess, reduce, and prevent marine debris and its adverse impacts on the marine environment.' The Act recognized that by-catch in active or 'ghost' (lost or unattended) fishing gear is a serious threat to many species (see Read et al. 2006, Macfadyen et al. 2009, Arthur et al. 2014) and that marine debris, in general, poses a significant threat to marine species and habitats. Impacts on cetaceans are well docu-

() The authors 2017. Open Access under Creative Commons by Attribution Licence. Use, distribution and reproduction are unrestricted. Authors and original publication must be credited. 
mented (Caswell et al. 1998, Garrison 2007, Jacobsen et al. 2010), as are those on sea turtles (Carr 1987, Chaloupka et al. 2004, Lewison \& Crowder 2007), pinnipeds (Stewart \& Yochem 1987, Jones 1995, Karamanlidis et al. 2008), and marine birds (Fry et al. 1987, Tasker et al. 2000, Bugoni et al. 2008). Sirenians also become entangled in fishing gear and other debris (dugongs: Heinsohn et al. 1976, Marsh 2000, Hines et al. 2012; manatees: Forrester et al. 1975, Hartman 1979, Beck \& Barros 1991). Cause of death in all taxa ranges from drowning in nets and fishing lines to ingestion of plastics, discarded line, and other objects. Additionally, marine debris and lost fishing gear pose a threat to marine habitats (Donohue et al. 2001, Arthur et al. 2014, Smith \& Edgar 2014). A majority of the cases represent offshore activities and debris (e.g. pelagic ghost nets, longline by-catch, plastics ingestion by ocean-faring seabirds), but entanglement in and ingestion of marine debris in the coastal and estuarine environment also threatens estuarine species, such as locally resident populations of bottlenose dolphins (Noke \& O'Dell 2002, Wells et al. 2008), as well as estuarine and coastal habitats (Uhrin \& Schellinger 2011). Manatees are primarily estuarine residents (but utilize freshwater and nearshore environments as well) and thus are subject to harm from active or lost fishing gear and other marine debris, and may serve as a 'sentinel' species for marine debris issues in the coastal and estuarine environment (sensu Bonde et al. 2004).

Originally listed under the Endangered Species Preservation Act of 1966, the West Indian manatee Trichechus manatus was further listed as Endangered under the Endangered Species Act of 1973 and by the International Union for Conservation of Nature (IUCN; Deutsch 2008). Further, the West Indian manatee is afforded additional protection by the Marine Mammal Protection Act of 1972 (MMPA). The MMPA establishes a moratorium on the taking of marine mammals, which includes harassing, hunting, capturing, killing, or attempting to harass, hunt, capture or kill any marine mammal. Despite these protections, the West Indian manatee still faces measurable threats to its long-term survival (Runge et al. 2015). Native to the coastal and estuarine waters of the southeastern USA, the Florida manatee subspecies T. m. latirostris lives in close proximity to humans who have significantly altered and impacted coastal habitats. Watercraft-related deaths are the leading cause of anthropogenic mortality (Rommel et al. 2007, Florida Fish and Wildlife Conservation Commission [FWC] 2014, Runge et al. 2015) and contribute greatly to the number of manatees rescued, although entanglement in marine debris has become a leading reason for rescuing and rehabilitating injured manatees in Florida (FWC and US Fish and Wildlife Service [USFWS] unpubl. data).

In 1985, the Florida Marine Research Institute (now the FWC's Fish and Wildlife Research Institute [FWRI]) assumed the lead for the Florida manatee carcass salvage and rescue program from the USFWS. The purposes of this program are to characterize and record necropsy information to determine causes of death and obtain information on manatee morphology, life history parameters, health, and physiology. A $24 \mathrm{~h}$ toll-free hotline for reporting wildlife resource issues, including sick, injured, or dead manatees, has been maintained by the state of Florida for decades. All reports regarding injured manatees or carcasses are investigated to the fullest extent possible. A centralized necropsy facility (FWRI's Marine Mammal Pathobiology Laboratory [MMPL]) opened in 1992 to allow staff to perform consistent, high quality, postmortem examinations of carcasses. Standardized necropsies are conducted to investigate cause of death and to collect biological and physiological data. FWRI maintains the Florida manatee mortality database, while rescue records are maintained in a centralized USFWS database. Manatee mortality and rescue records provide direct (e.g. actual entanglement or ingested marine debris) and indirect (e.g. observation of scars or amputations related to prior entanglement) evidence of interaction with marine debris, often those types associated with the fishing industry (both commercial and recreational; see Smith 1997).

By examining the manatee mortality and rescue databases together, impacts of entanglement and marine debris may be quantitatively assessed and evaluated. These databases provide detailed information on manatees that have been affected by marine debris in the environment. Understanding the demographics of manatees frequently impacted by marine debris and the items most commonly encountered by manatees may help to inform population threats analyses and the efforts directed toward reducing this threat to manatees, as well as other fauna and the estuarine environment. This study builds on previous work (Adimey et al. 2014) by including information from over 2800 additional records, within an expanded study period, including evidence of manatee interaction with non-fishery debris as well as fishery gear cases, examining entanglement and ingestion cases separately, independently analyzing live (i.e. rescue) and dead (i.e. necropsy) cases, quantifying lethal entanglement 
and ingestion cases, and refining the spatial (geographic) characterization of such cases in Florida. A better understanding of the dynamics of entanglement in and the ingestion of marine debris by manatees serves as an example of the impacts of marine debris on a primarily estuarine species and may allow for the development of preventative strategies to reduce the overall risk to the manatee population and other estuarine fauna and habitats.

\section{METHODS}

We examined Florida manatee mortality and rescue records from a $20 \mathrm{yr}$ period (1993 through 2012) for incidences of entanglement in fishing gear and other marine debris (e.g. ropes, plastics, nets) and for instances of marine debris ingestion (e.g. fishing lines, hooks, plastics, other foreign objects). Mortality records are specifically useful for detecting ingestion cases and generally useful for assessing entanglement cases (often via scar evidence). Rescue reports are more likely to provide specific information on the type of gear or marine debris associated with an entanglement, as most entangled manatees that are rescued still carry identifiable gear. This allows for gear to be attributed to appropriate categories and, if applicable, to the appropriate fishery.

We examined cases of manatee entanglement and marine debris ingestion to identify gear type, geographic location, manatee size, sex, and point of entanglement. We categorized gear as either fisheryrelated (trap lines, fishing lines, hooks and lures, nets, lead weights, leaders, etc.) or non-fishery-related (i.e. marine debris that was not or could not specifically be connected to a fishery). In Florida, trap fisheries are primarily comprised of blue crab (Callinectes sp.), stone crab (Menippe mercenaria) and spiny lobster (Panulirus argus) traps. Non-fishery debris included miscellaneous rope, plastics, rubber, and other items. Geographic location was the actual carcass recovery or rescue location (but not necessarily where the individual died or initially become entangled). Sex, when known, was recorded (sex often could not be determined for rescued manatees only observed or assisted in the water). Manatee size classes (when individuals could be measured) were based on straight-line total length and defined as: calf $<235 \mathrm{~cm}_{i}$ juvenile 235-264 $\mathrm{cm}_{i}$ and adult $>264 \mathrm{~cm}$ (Bonde et al. 2012), or were estimated in the field. We analyzed the data to estimate temporal trends and categorical differences using linear models in Microsoft Excel (Office 2013; Dowdy \& Wear- den 1991, Sokal \& Rohlf 1995) and the statistical program R (ver 3.1.1; Crawley 2007). Model results were compared using Akaike's information criterion (AIC; Akaike 1973) with the smallest value of AIC generally accepted as best.

\section{RESULTS}

\section{Mortality reports}

From 1993 through 2012, 6893 Florida manatees were recorded and cataloged into the FWRI manatee mortality database, most of which were examined at the MMPL or, to a lesser extent, in the field by FWRI biologists. A total of 332 records was removed from the analyses because they either occurred outside of Florida (and were not necropsied by FWRI staff), consisted only of partial remains and could not be fully examined, or were verified carcasses that were not recovered for various reasons (e.g. extremely remote location, being guarded by alligators), leaving a total of 6561 mortality records for examination. In the FWRI manatee mortality database, deaths due to entanglement or ingestion of marine debris are categorized as 'Human, Other' ( $\mathrm{n}=125$ in the dataset examined). Within this category, we found 37 cases of ingestion of marine debris and 13 cases of entanglement as the probable cause of death. In addition, 101 carcasses from other cause of death categories in the mortality database had some degree of external evidence of entanglement (e.g. active entanglement, entanglement scars, missing flipper(s) caused by entanglement) and 598 manatees had marine debris in their gastrointestinal (GI) tracts, but the object(s) was/were not lethal or the primary cause of death (i.e. non-lethal ingestion of marine debris).

During the study period, the overall number of reported manatee carcasses increased significantly by year, including those without signs of entanglement or ingested debris (i.e. all other cases), those with ingested marine debris, and those with evidence of entanglement (Fig. 1). In relation to the total number of reported carcasses, however, the percentage of cases per year with evidence of entanglement remained relatively constant, at around $2 \%$, whereas the percentage of cases with ingested marine debris did appear to increase over time (Fig. 2). Overall, from 1993 to 2012, carcasses with ingested marine debris or evidence of external entanglement (e.g. attached line, scars, amputations) comprised about $11 \%$ of all examined carcasses (Table 1); however, ingestion of marine debris and entanglement com- 

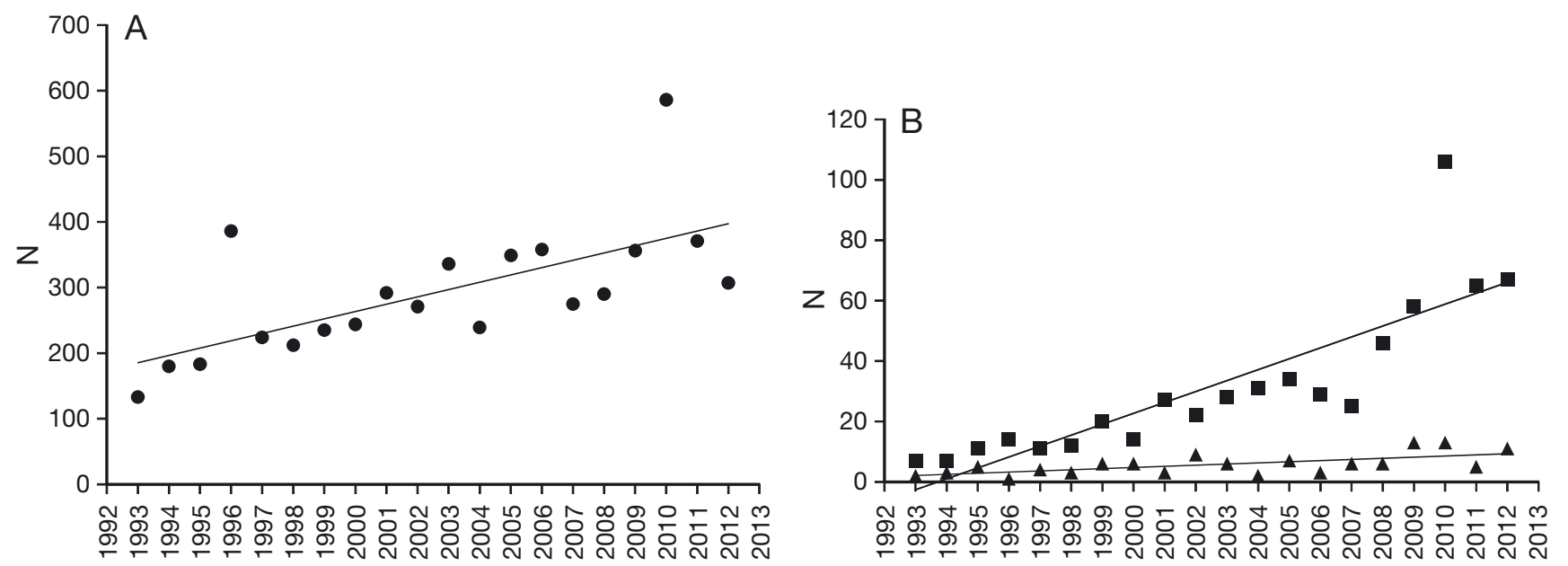

Fig. 1. (A) Annual manatee Trichechus manatus latirostris deaths reported in Florida, USA, 1993 to 2012, with cases involving entanglement or ingestion of marine debris removed (i.e. all other cases). Increase over time is significant ( $p=0.001$; slope $=$ 11.12; $\left.\mathrm{R}^{2}=0.44\right)$. (B) Annual manatee deaths reported in Florida, 1993 to 2012, that showed evidence of entanglement ( $\left.\mathbf{\Delta}\right)$ or ingestion of marine debris $(\boldsymbol{\square})$. Marine debris ingestion increased significantly $\left(\mathrm{p}<0.0001\right.$; slope $\left.=3.61 ; \mathrm{R}^{2}=0.71\right)$, as did entanglements $\left(p=0.002 ;\right.$ slope $\left.=0.38 ; R^{2}=0.42\right)$

bined were directly responsible for less than $1 \%$ of all manatee deaths. As a cause of death, neither ingestion of marine debris $\left(\mathrm{p}=0.21\right.$; slope $=0.06 ; \mathrm{R}^{2}=$ $0.09)$ nor entanglement $\left(p=0.60\right.$; slope $=0.02 ; R^{2}=$ 0.02 ) appeared to increase over time.

In all cases, the most common foreign object found during manatee necropsy was monofilament fishing line, occurring in 412 cases. Plastics of various types were identified in 204 carcasses. Fishing hooks or lures were detected in 23 carcasses. Other debris included fabrics or man-made sponges, string, rope,

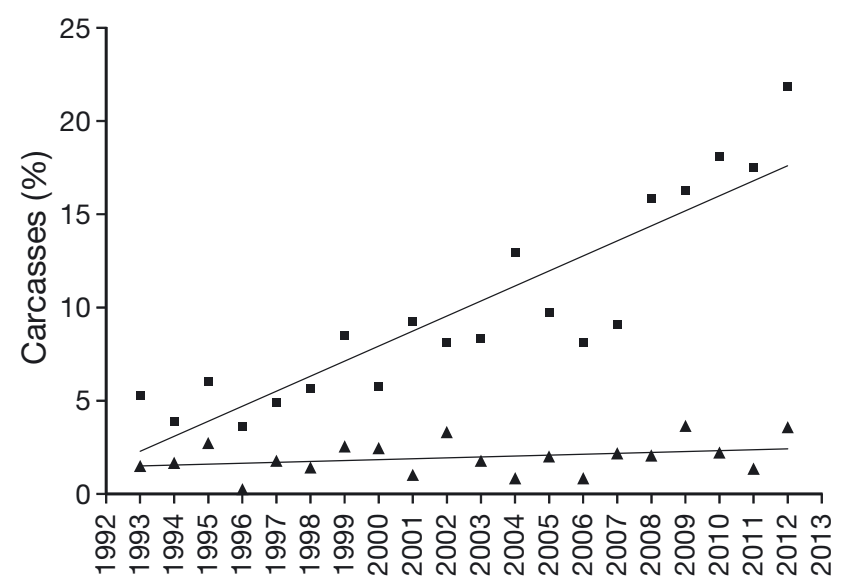

Fig. 2. Percentage of Florida manatee Trichechus manatus latirostris carcasses, 1993 to 2012, that showed evidence of entanglement ( $\mathbf{\Lambda})$ or ingestion of marine debris ( $\mathbf{\square})$. Evidence of entanglement remained relatively constant (mean $=1.96$, $\mathrm{SD}=0.91 ; \mathrm{p}=0.18 ;$ slope $=0.05 ; \mathrm{R}^{2}=0.09$ ), whereas ingestion of marine debris increased significantly over time (mean $=9.94, \mathrm{SD}=5.31 ; \mathrm{p}<0.0001 ;$ slope $=0.81 ; \mathrm{R}^{2}=0.80$ ) wire, balloons, rubber gloves, polystyrene foam, decorative plastic grass, and, on 1 occasion, a condom. The most common location for ingested marine debris was the large intestine, specifically the colon, followed by the stomach. Marine debris in the small intestine, however, was most lethal (24 deaths out of 79 cases where marine debris was found in the small intestine).

Pathology of the 37 fatal cases of foreign object ingestion included intussusception ('telescoping' of part of the intestine into itself), impaction, obstruction, and perforation of the GI tract. Fishery-related items (sometimes multiple items per case, thus total is $>37$ ) included monofilament fishing line $(\mathrm{n}=24)$, hooks $(\mathrm{n}=17)$, braided fishing line $(\mathrm{n}=3)$, and netting $(\mathrm{n}=1)$. The remaining lethal cases included other marine debris such as plastics $(n=8)$, rope $(n=2)$, sponges $(n=2)$, cloth $(n=2)$, and other items $(n=4)$. Fishery-related items were associated with $81 \%$ of marine debris ingestion deaths and primarily consisted of monofilament fishing line, often in association with hooks.

In the 13 cases of external entanglement causing death, 6 manatees died as a result of a secondary infection related to the entanglement. Five manatees were known to have drowned in nets, although only 1 was fishery-related; 3 manatees accidentally died in research nets and 1 manatee died immediately following a net-based rescue (possible capture myopathy). Additionally, 2 manatees died as a result of being tethered in place by unidentified rope (i.e. the manatee was attached to an immovable object via 
Table 1. Entanglements in and ingestion of marine debris by Florida manatees Trichechus manatus latirostris, 1993 to 2012. Total numbers are presented by sex and size class (calves: $<235 \mathrm{~cm}$, juveniles: $235-264 \mathrm{~cm}$, adults: $>264 \mathrm{~cm}$ total length, and those of unknown length [Unk]) and include those individual cases associated with entanglement in marine debris, ingestion of marine debris, and all other cases. In necropsy cases, 'Entanglement' indicates actual or evidence of (e.g. scars or missing flipper) entanglement (whether or not it was the actual cause of death), and 'Ingestion' indicates observation of marine debris in the GI tract during necropsy. In rescue cases, 'Entanglement' in marine debris was the primary reason for rescue (actual entanglement) or, occasionally, the secondary reason (e.g. calf of an entangled mother), and 'Ingestion' comprises cases where a hook or lure was known to be inside the mouth or oral cavity, marine debris was passed during rehabilitation, or marine debris was later discovered during necropsy of an animal that died during rehabilitation

\begin{tabular}{|c|c|c|c|c|c|c|c|c|c|c|c|c|}
\hline \multirow{2}{*}{$\begin{array}{l}\text { Size class } \\
(\mathrm{cm})\end{array}$} & \multicolumn{4}{|c|}{ Entanglement- } & \multicolumn{4}{|c|}{ Ingestion -} & \multirow{2}{*}{ Females } & \multicolumn{2}{|c|}{ _All others - } & \multirow[b]{2}{*}{ Total } \\
\hline & Females & Males & Unk & Total & Females & Males & Unk & Total & & Males & Unk & \\
\hline \multicolumn{13}{|l|}{ Necropsies } \\
\hline$<235$ & 9 & 7 & 0 & 16 & 100 & 110 & 0 & 210 & 1357 & 1565 & 73 & 2995 \\
\hline $235-264$ & 9 & 6 & 0 & 15 & 56 & 47 & 1 & 104 & 310 & 450 & 22 & 782 \\
\hline$>264$ & 67 & 16 & 0 & 83 & 200 & 121 & 0 & 321 & 1005 & 969 & 61 & 2035 \\
\hline Unknown & 0 & 0 & 0 & 0 & 0 & 0 & 0 & 0 & 0 & 1 & 0 & 1 \\
\hline Total & 85 & 29 & 0 & 114 & 356 & 278 & 1 & 634 & 2672 & 2985 & 156 & 5813 \\
\hline \multicolumn{13}{|l|}{ Rescues } \\
\hline$<235$ & 27 & 27 & 40 & 94 & 3 & 1 & 1 & 5 & 178 & 191 & 29 & 398 \\
\hline $235-264$ & 31 & 11 & 15 & 57 & 1 & 2 & 0 & 3 & 70 & 93 & 9 & 172 \\
\hline$>264$ & 71 & 11 & 20 & 102 & 5 & 1 & 0 & 6 & 189 & 129 & 15 & 333 \\
\hline Unknown & 5 & 0 & 43 & 48 & 1 & 0 & 0 & 1 & 4 & 3 & 18 & 25 \\
\hline Total & 134 & 49 & 118 & 301 & 10 & 4 & 1 & 15 & 441 & 416 & 71 & 928 \\
\hline
\end{tabular}

entanglement and died as a result). Overall, fishery gear accounted for $46 \%$ of entanglement deaths.

Geographically, manatee carcasses with marine debris in the GI tract were most prevalent in Brevard and Lee Counties (Fig. 3A). Correspondingly, both of these counties led in manatee deaths caused by ingested debris ( $\mathrm{n}=7$, Lee; $\mathrm{n}=6$, Brevard). These counties are also the 2 counties with highest overall number of reported manatee deaths. Notably, Broward County ranked 3rd for carcasses with ingested marine debris yet ranked 15th in overall deaths. Similarly, Palm Beach County ranked 5th in carcasses with ingested marine debris but was 16 th in overall deaths. Carcasses with evidence of prior entanglement showed a similar geographic pattern, with the top 2 counties also being Brevard and Lee Counties (Fig. 3B). Similar to ingestion cases, both Broward and Palm Beach Counties ranked higher in carcasses with evidence of prior entanglement (6th and 4th, respectively) than they did in overall number of dead manatees (15th and 16th, respectively).

Demographically, in terms of sex, the manatee mortality database comprised $50.2 \%$ male manatees and $47.4 \%$ females $(2.4 \%$ were of unknown sex, mostly due to advanced post-mortem decomposition at time of examination; Table 1). For cases involving ingestion of marine debris, however, $43.8 \%$ were males and $56.1 \%$ were females (with 1 of undetermined sex). Using a linear model approach, a sex-based model was more explanatory than the null model (i.e. sex not considered; AIC scores of 18.97 and 34.97, respectively). Overall, the model predicted that male carcasses would have an $8.5 \%$ occurrence of marine debris in the GI tract (95\% CI = 7.5-9.4\%), while female carcasses would have an $11.7 \%$ occurrence of marine debris in the GI tract ( $95 \% \mathrm{CI}=10.6-12.9 \%$ ). For cases involving evidence of external entanglement, 25.4\% were males and $74.6 \%$ were females. Again, using the linear model approach, a sex-based model was more explanatory than the null model (AIC scores of 15.45 and 47.97, respectively). Overall, evidence of active or previous external entanglement was predicted in $1.0 \%$ (95\% CI $=0.6-1.3 \%)$ of male carcasses, while evidence of active or previous external entanglement was predicted in $3.1 \%(95 \% \mathrm{CI}=2.4-3.7 \%)$ of female carcasses.

The size distribution of dead manatees without marine debris in the GI tract or evidence of external entanglement (i.e. all other cases) appears to be dominated by calves, followed by adult manatees (Table 1). Adult female manatee carcasses, however, dominated those cases with ingested marine debris and evidence of entanglement when compared to adult males (Table 1).

\section{Rescue reports}

From 1993 through 2012, 1244 manatee rescue reports were filed. Of these, 271 were categorized as 

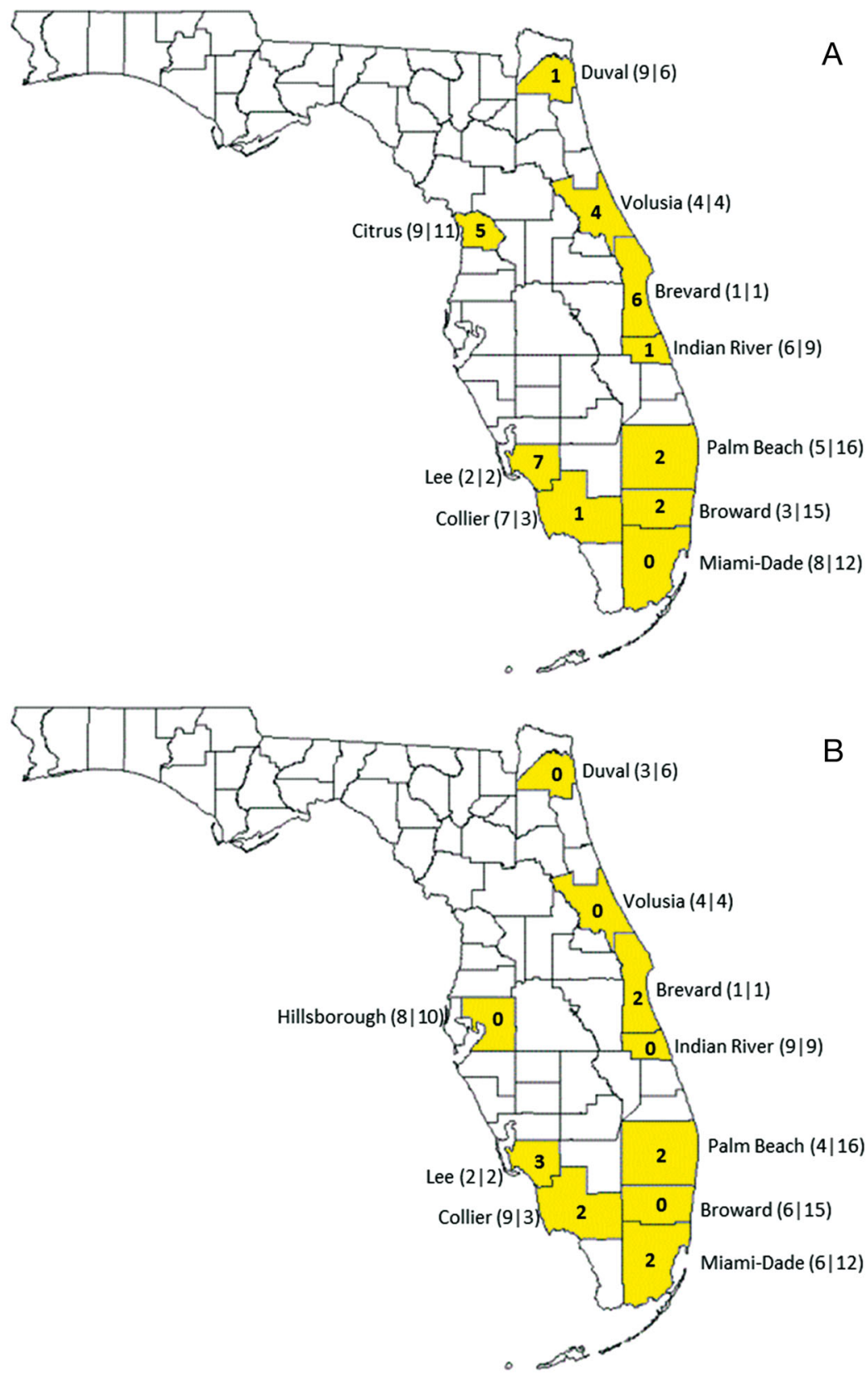

Fig. 3. Geographic (Florida county) locations of Florida manatee Trichechus manatus latirostris carcass recoveries, 1993 to 2012. Top 10 counties (A) with manatee carcasses having ingested marine debris and (B) with carcasses having evidence of current or prior entanglement (e.g. scars, amputations). In both figures, county rank is given in parentheses next to county name and followed by overall rank in statewide manatee mortality (separated by 'I'). The total number of deaths where foreign object ingestion (A) or entanglement (B) was the cause of death is given inside each county in bold type (e.g. Broward County had 2 deaths due to ingested marine debris, ranked 3rd in carcasses with ingested marine debris and 15th overall in mortalities)

entanglements. These rescues comprised typical entanglements in fisheries gear (e.g. traps, fishing line) or other marine debris (e.g. ropes, straps). Overall, during the study period, entanglement was the second leading cause for rescue and accounted for
$21.8 \%$ of all rescues, followed closely by watercraft injury $(20.0 \%)$. The number 1 overall reason for rescue during this time was for natural causes $(28.9 \%)$, which can include orphaned calves, cold-stress syndrome, and red tide intoxication. Further investigation of the rescue database revealed additional rescues not specifically categorized as entanglements but nonetheless were related to entanglement in some way. There were 14 dependent calves of entangled cows and 2 mothers of entangled calves. These manatees would not have been rescued were it not for the entanglement of the mother or calf in these closely bonded pairs (which are normally rescued together). There were 10 rescue cases categorized as 'Human, Other' that involved fishing hooks or lures. In 4 cases (1 rescued for entrapment, 1 for natural causes, and 2 for watercraft injury), an entanglement was identified but ancillary to the main reason for rescue; these cases were included in our analyses. Altogether, 301 cases were analyzed (Table 1). During the study period, the overall number of rescues performed increased significantly per year, with rescues for reasons other than entanglement increasing at a faster rate than entanglement-related rescues (Fig. 4).

Of the 301 cases of manatee entanglement and related rescue cases, $49.5 \%$ involved entanglements in trap lines, usually braided nylon or polypropylene. For an incident to be classified as trap-related, the presence of a float with appropriate trap registration number, a trap (or part of one), or a combination of float and trap associated with the line is required. Monofilament fishing line was involved in $26.9 \%$ of entanglements and entanglement-related rescues. Other ropes (i.e. ropes not specifically attributable to traps or other fisheries) were implicated in $13.0 \%$ of entanglements, including anchor lines, mooring lines, boat fender float lines, construction silt fencing anchor lines, and nylon and polypropy- 


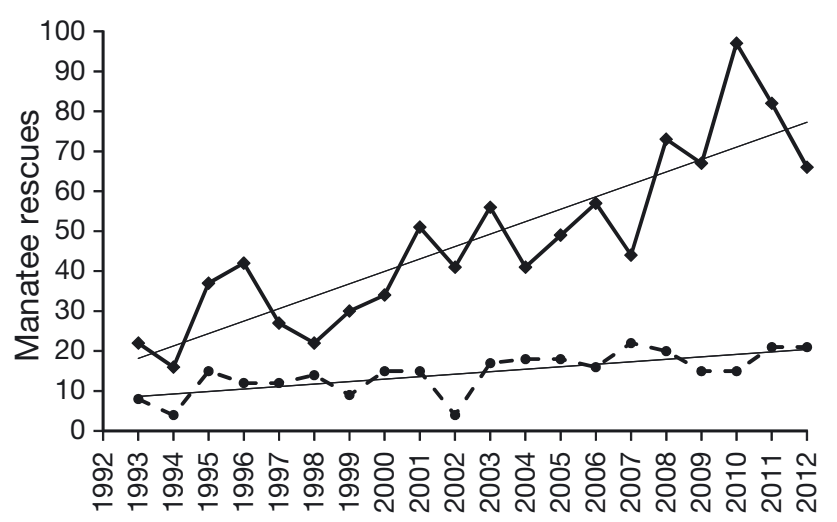

Fig. 4. Annual manatee Trichechus manatus latirostris rescues in Florida, 1993 to 2012. Overall, the number of manatee rescues per year increased, with non-entanglement related rescues (—-) showing a steeper increase $(\mathrm{p}<$ 0.00001 ; slope $\left.=3.11 ; R^{2}=0.75\right)$ when compared to entanglement-related rescues $(-\bullet-; p=0.0005$; slope $=0.62$;

$$
\left.\mathrm{R}^{2}=0.50\right)
$$

lene lines of different lengths and unknown origin. Of the remaining rescues, nets were involved in $6.6 \%$ of the cases and hooks were found in $4.0 \%$. The net category included entanglement in cast nets $(\mathrm{n}=$ 12), non-manatee-related research nets (i.e. manatees were not the study subject; $\mathrm{n}=3$ ), and 1 shrimp net. These data do not include intentional captures of manatees during manatee-related research activities. Nineteen rescue reports indicated entanglement in more than 1 type of gear. Often hooks and monofilament or braided fishing line occurred together. The maximum number of gear types (not individual pieces of gear) carried by 1 individual at the same time was 3. Overall, $87.0 \%$ of marine debris entanglement involved fisheries gear (e.g. trap line, monofilament line, hooks/lures, trot lines, or fishing nets).

The most common body location for entanglement was around one or both flippers (Table 2). Flippers (left, right, both or unspecified in the record) were involved in $61.2 \%$ of entanglement cases. When only 1 flipper was entangled, left and right entanglements were evenly distributed $(24.2$ and $23.6 \%$, respectively). Body wraps were second most common, accounting for $19.7 \%$ of entanglements. Other locations were the fluke (including wraps around the peduncle; $9.7 \%)$, the head and mouth region $(4.2 \%)$, and fouled tracking gear $(2.9 \%$; manatee tracking gear typically consists of a peduncle belt, tether, and attached floating tracking device). In 7 cases $(2.3 \%)$, the location of the entanglement was not reported by the rescuing agent (these were citizen-initiated and reported rescues). In 25 cases, multiple regions
Table 2. Location of anthropogenic entanglements on Florida manatee Trichechus manatus latirostris rescues, 1993 to 2012, by sex (females: F; males: M; unknown: Unk). Total occurrences and percentage of total is presented. Sometimes multiple body locations were affected by the entanglement and each location is counted (i.e. 1 manatee may account for 2 or more entries in the table below). 'Gear' refers to scientific tracking equipment, consisting of a belt, tether and tracing device. In some cases, the point of attachment of the entanglement was unknown (or unreported)

\begin{tabular}{|lrrrrr|}
\hline $\begin{array}{l}\text { Location } \\
\text { on body }\end{array}$ & F & M & Unk & Total & $\%$ \\
\hline Head/face & 1 & 2 & 10 & 13 & 4.2 \\
Flippers & & & & & \\
$\quad$ Left & 43 & 19 & 13 & 75 & 24.2 \\
Right & 40 & 7 & 26 & 73 & 23.5 \\
Both & 18 & 4 & 6 & 28 & 9.0 \\
Unspecified & 0 & 2 & 12 & 14 & 4.5 \\
Body & 19 & 9 & 33 & 61 & 19.7 \\
Peduncle/fluke & 7 & 2 & 21 & 30 & 9.7 \\
Gear & 6 & 3 & 0 & 9 & 2.9 \\
Unknown & 1 & 0 & 6 & 7 & 2.3 \\
\hline
\end{tabular}

(head, body, flippers, fluke, or tracking gear) of the manatee were entangled simultaneously. Loss of a flipper was noted in 10 cases (either the flipper was noted missing in subsequent re-sightings or traumatically amputated during rescue for the entanglement).

With respect to geographic location, Brevard and Monroe Counties accounted for the most entanglement rescues (Fig. 5). Brevard County also was highest in overall manatee rescues during the study period. Monroe County in the Florida Keys accounted for the second highest entanglement rescue total but was 9th for manatee rescues overall. Monroe County had the highest number of monofilament entanglements but recorded no trap entanglements. Conversely, the central and southern west coast of Florida (Citrus to Lee Counties) had 80 trap entanglements (those depicted in Fig. 5 and 7 in other west coast county not in the top 10) and only 5 reported monofilament entanglements. Brevard County recorded the most trap entanglements by county and had the second highest number of monofilament entanglements.

Sex was determined in $84.7 \%$ of all documented manatee rescues during the sampling period (Table 1). For entanglement rescues, $60.5 \%$ were identified by sex (dis-entanglements frequently occur in the water without an opportunity to determine sex), with males comprising $26.8 \%$ and females $73.2 \%$. Using a linear model approach, a sex-based model was more explanatory than the null model (AIC scores of 16.08 and 44.62, respectively). Overall, 


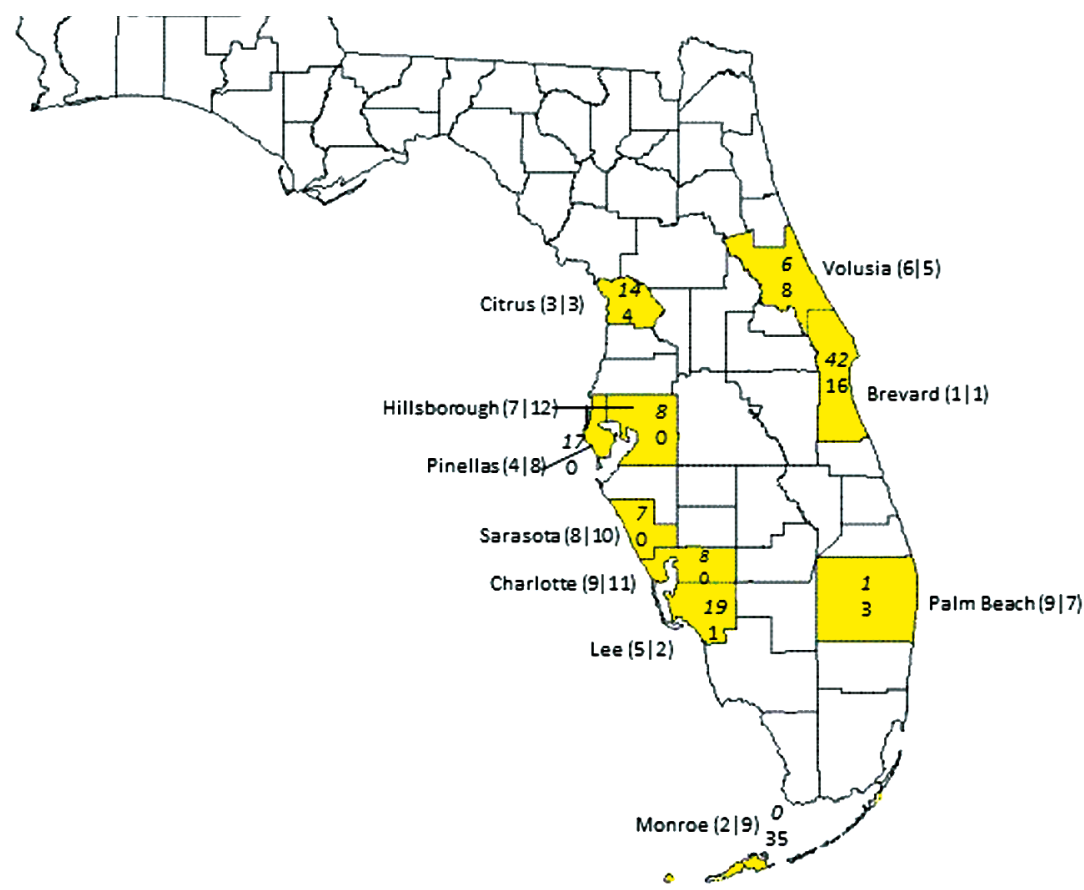

Fig. 5. Top 10 geographic (Florida county) locations of Florida manatee Trichechus manatus latirostris entanglement rescues, 1993 to 2012. County rank is given in parentheses next to county name and is ordered as rank in entanglement rescues followed by overall rank in statewide manatee rescues (separated by 'l'). The total number of trap entanglement rescues (top number, italics) and monofilament entanglement rescues (bottom number) is given inside (or next to) each county (e.g. Monroe County ranked 2nd in entanglement rescues and 9th in overall rescues; there were no trap entanglement rescues and 35 monofilament entanglement rescues in the county)

debris (sometimes more than 1 type; Table 1). In these cases, hooks were most common, followed by monofilament line, and other marine debris (including various plastics, lead weights, and fabric). Of these rescued individuals, 8 died during rehabilitation; 4 of the deaths were directly related to the ingested foreign object. Fishery-related gear was involved in 12 of the 15 rescues, again dominated by female manatees.

\section{DISCUSSION}

Throughout the 20 yr dataset examined, entanglement in and ingestion of marine debris demonstrably impacted the Florida manatee, highlighting the continuing problem of marine debris in the estuarine environment. Although interaction with marine debris was the primary cause of death for less than $1 \%$ of the manatee carcasses examined, it was the leading anthropogenic reason for manatee rescue during this timeframe. We found that fisheries-related gear could be attributed to most ingestion-related deaths

the model predicted that rescued males had a $10.2 \%$ chance of entanglement (95\% CI $=7.4-13.0 \%)$, while rescued females had a $22.9 \%$ chance of being entangled (95\% CI $=19.4-29.4 \%$ ).

Size distribution of manatees in the rescue database without evidence of external entanglement had a bimodal distribution for females and males, with most cases occurring at the calf and adult size classes (Table 1). Among entangled manatees, adult female cases were most prevalent, whereas incidences of male entanglement cases were more prevalent at the calf stage. Manatees of unknown sex also peaked in the entanglement database as calves.

Typically, manatees are not rescued specifically for marine debris ingestion. In most rescue cases where ingested marine debris was ultimately discovered, the foreign object discovery occurred during veterinary care and treatment or later during necropsy; however, in 2 cases, a fish hook or lure was known to be inside the manatee's mouth, and each was rescued so the hook could be removed. Overall, in addition to the 301 entanglement-related rescues, 15 rescues were determined to involve ingested marine and accounted for the majority of entanglement rescues performed. Further, monofilament fishing line was the single most common foreign object found in manatee carcasses. Interestingly, female manatees were found to be more at risk from marine debris, with more females than males ingesting and becoming entangled in marine debris.

In the mortality database, as a cause of death, we found that females were more vulnerable than males to entanglement in and ingestion of marine debris. Similarly, female manatees (particularly adult females) were more often the subject of entanglementrelated rescue, significantly more so than males. Size distributions of dead manatees with ingested marine debris or evidence of external entanglement overlapped the general size distribution of recovered manatee carcasses but tended to be dominated by larger (adult) individuals. Naturally, larger manatees consume more food (5 to $10 \%$ of their body weight per day; Reep \& Bonde 2006) than do smaller manatees and have a greater chance of accidentally ingesting marine debris mixed with or entangled in the vegetation that they eat. Similarly, most rescued 
female manatees tended to be adults. Larger manatees tend to be older (Marmontel et al. 1996) and so have had more opportunity to encounter and become entangled in fisheryrelated or other marine debris. The significant disparity in the higher number of adult females than males that become entangled may support the hypothesis that pregnant or lactating females intentionally rub against rope or heavy line in the environment to try to relieve milkengorged teats (located at the flipper axilla), occasionally becoming entangled in the process (Beck \& Lefebvre 1995).

Several rescued manatees exhibited evidence of multiple entanglements, as well as healed entanglement wounds (e.g. missing flippers, scars). A persistent entanglement may become an irritant that causes a manatee to re-entangle while seeking relief, as when rubbing affected flippers against rope

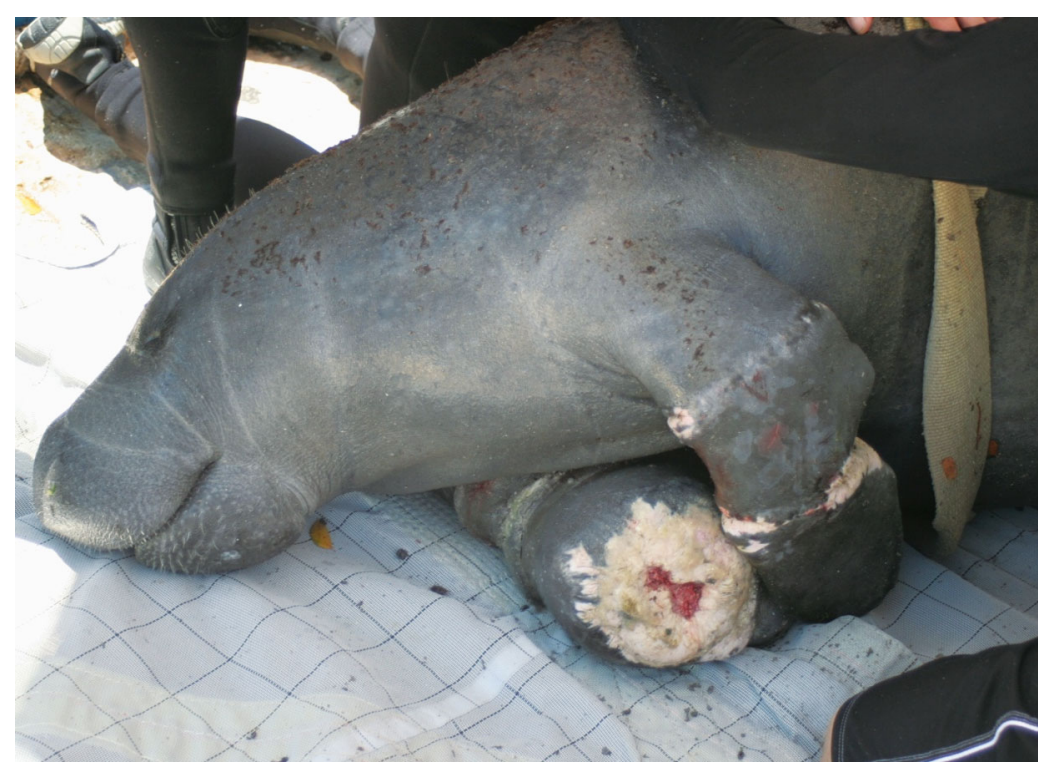

Fig. 6. Serial entangling manatee Trichechus manatus latirostris, from the Florida Keys, Monroe County, showing a partially amputated and swollen right flipper, a healed entanglement scar on the upper left flipper, and an entanglement wound on the lower left flipper, the reason for rescue here. From 1993 to 2012, this manatee was rescued 7 times for entanglement. All 7 occasions included monofilament on 1 or both flippers. Photo credit: FWC files; all activities were conducted under the USFWS permit \# MA770191 or lines. For example, several rescued manatees had trap line or other rope entanglements over existing, long-term monofilament entanglements. Manatees tend to isolate injuries (e.g. an entanglement wound) with a fibrotic reaction (scar tissue), reducing the possibility of systemic infection (and possible death through sepsis), but this process may not resolve the issue (e.g. the entanglement remains) or the scar tissue itself may become irritating (Harr et al. 2006). These healed injuries may also create irregularities (swollen scar tissue) or notches along flipper or tail margins that may be more likely to catch or entangle additional line or debris. This was particularly evident in 2 serial monofilament entanglement cases observed in the Florida Keys. These 2 individuals, both females, have been rescued over 7 times each for monofilament, fishing lure, and rope entanglements. In each case, both flippers have become swollen with scar tissue and are notched at points of previous entanglements. One of these females underwent surgical amputation of part of the right flipper as a result of entanglement (Fig. 6). That particular manatee was killed in a watercraft collision in 2016 and had active monofilament and other fishing line entanglements on both flippers and a large amount of monofilament fishing line segments in the GI tract. Both flippers were malformed from chronic entanglements. This female had been nursing twin calves prior to death, but on necropsy, the right teat was much smaller than the left and no milk was grossly observed in the mammary gland, suggesting that the severely misshaped flipper could have interfered with calf nursing. This finding demonstrates potential sublethal effects of marine debris entanglement, possibly with generational impacts, including reduced fitness of offspring if access to sufficient nutrition via nursing is impacted by active or chronic entanglement.

Evidence of external entanglement in marine debris noted during manatee necropsy appeared to remain relatively constant (in about $2 \%$ of cases per year) during the $20 \mathrm{yr}$ study period; however, documentation of marine debris in the GI tract of dead manatees appeared to increase during the study. Over the entire study period, around $10 \%$ of manatees had internal marine debris noted upon necropsy but in the final $5 \mathrm{yr}$ of the period (2008 to 2012), the average percentage of cases with marine debris discovered in the GI tract increased to $17.9 \% \mathrm{yr}^{-1}$ (SD = 2.36; Fig. 2). The reasons for this seemingly sharp increase in discovery of ingested debris are unclear and likely a combination of factors (e.g. availability, detection). Despite this, the rate of lethal marine debris entanglement or ingestion (i.e. as a cause of death) remained steady and did not appear to change during the study period. 
In general, fishery-related gear dominated the foreign objects found internally and directly caused $81 \%$ of deaths related to ingested marine debris; monofilament fishing line was the most common type of marine debris found during manatee necropsy. The types of gear most commonly associated with manatee entanglement rescues were trap line and monofilament fishing line. Both objects are common in the marine environment in Florida (Laist 1987, Ocean Conservancy 2009, Ribic et al. 2010), and because Florida is the top recreational fishing destination in the USA (US Department of the Interior et al. 2014), there is plenty of opportunity for lost or discarded monofilament to end up in coastal waters and become a hazard. Although more manatees appear to become entangled in trap line than in monofilament line, the number of manatees that become entangled in monofilament may be underrepresented. Also, an unknown percentage of unidentifiable rope entanglements are likely fishery-related as well but could not be definitively identified as such. Further, the data do not account for imperfect detection and therefore indicate a minimum count of affected individuals. Comparatively, trap line entanglements tend to be highly visible as a result of the trap itself or a surface-resting float attached to the line. Additionally, trap line tends to be large, braided line, typically white or yellow (but sometimes black), while monofilament is almost transparent in the water. As a result, a monofilament entanglement may go unnoticed until the damage is extensive or additional debris accumulates on the entanglement (often forming a monofilament 'nest' of natural and anthropogenic debris).

Geographically, Brevard and Lee Counties had the highest number of recovered carcasses and also had the most cases of ingested marine debris and external evidence of entanglement. These 2 counties also support large numbers of manatees, especially during the winter (Martin et al. 2015). Two other counties (Broward and Palm Beach), however, were ranked in the top 10 for cases of marine debris ingestion and evidence of entanglement but were not ranked nearly as high in overall mortality records. These are the second and third most populous counties in Florida (US Census Bureau 2010). The results may be coincidental but may also reflect the conditions of the waterways in these dense urban areas, where incidence of marine debris is likely to be higher. Miami-Dade County, Florida's most populous county, ranked 8th in ingestion cases and 7 th in cases with evidence of entanglement but 12 th in overall manatee deaths.
Of note, the geographic distribution of trap line rescues differed from monofilament-related rescues. Although trap line rescues occurred on both the east and the west coasts of Florida, no trap line rescues have been recorded in the Florida Keys (through 2012, as analyzed herein). During the study period, Lee and Brevard Counties led the state, respectively, in blue crab commercial fishery landings (FWC 2013) and also in entanglement rescues. Citrus and Charlotte Counties were in the top 5 in blue crab landings for the state and also high in documented manatee entanglements (Fig. 5). High incidence of trap line entanglements appear to coincide with areas of high trap fishing effort, with the notable exception of the Florida Keys (Monroe County). Monroe County (the Florida Keys portion) consistently leads the state in lobster and stone crab commercial landings, with the lobster catch frequently exceeding that of the next 4 to 5 counties combined (FWC 2013). The area also is a 'hotspot' for sea turtle entanglements in trap and pot gear (Adimey et al. 2014). Lack of manatee trap entanglements in the Florida Keys may be due, in part, to the differences in the bottom substrate where traps are typically deployed. Compared with the Keys, crabbing on the central-east and west coast of Florida is more concentrated in or near seagrass beds or along shorelines where manatees frequently travel. Commercial trapping in the Keys (primarily for lobster and stone crab) tends to occur in deeper areas where seagrass is scarce and reef and hard-bottom habitats are abundant. Crab trap deployment in or near seagrass beds increases the likelihood of manatees encountering them while grazing in the same habitat. Additionally, manatees are naturally curious about novel objects in their environment and are frequently observed manipulating ropes and lines with their flippers and mouth (Bowles et al. 2001), utilizing the sensitive vibrissae in the oral disc for examining objects (Marshall et al. 1998, Bachteler \& Dehnhardt 1999). This inquisitive nature may contribute to the number of trap line and unspecified rope-related entanglement cases.

Monofilament-related rescues have been documented along the east coast of Florida (primarily Brevard County) and in the waters of the Florida Keys (as shown here, but see also Adimey et al. 2014). Both areas are considered 'fishing hotspots' in Florida (Visit Florida ${ }^{\circledR}$ 2014). Such entanglements appear to be relatively uncommon along the west coast of Florida, although reasons for this disparity are unclear, since recreational fishing is highly popular there as well. Increased visibility in the Florida Keys, resulting from the especially clear water, may partly ex- 
plain the increased number of observed (and hence reported) entanglements there. Photo-identification and other sighting data indicate that there are manatees on the west coast bearing evidence of previous or active monofilament entanglements (FWRI and United States Geological Survey-Sirenia Project unpubl. data), but monofilament-related rescues in these areas remain rare. Brevard County waters support manatees year-round and contain a primary overwintering area for large numbers of manatees (Deutsch et al. 2003, Martin et al. 2015); the numbers of entanglements there may be a factor of the number of manatees using the area (i.e. more manatees, more observed entanglements).

The overall numbers of rescues and reports of dead manatees increased during the study period, as did those specific to entanglement in fishing gear and other marine debris. Documenting evidence of entanglement (observing entanglement scars or missing flippers) and locating and identifying marine debris during necropsy are detection-based endeavors (i.e. scars or debris must be discovered by examiners and detection rates may vary over time and with each examiner), just as reports of entangled manatees must be received from the public and then verified (and hopefully rectified) by researchers. Reporting is a function of 3 factors: abundance of manatees in a region, the numbers of injuries/deaths, and reporting/discovery of those injured/dead manatees. Changes in any of these components can cause the number of reports to fluctuate. For example, carcass recovery rates may vary given differences in waterway characteristics such as depth, water clarity, quantity of shoreline vegetation, and the number of people using the areas (Calleson 2014). Additionally, an unknown number of unreported, citizen-initiated rescues or rescue attempts probably occur. Finally, certain gear types may be more noticeable (e.g. a trap with heavy line and float as compared to a few strands of thin, clear, monofilament wrapped around a flipper), thus passively biasing the reporting rate.

Some limitations should be considered when interpreting trends and patterns over time in both the mortality and rescue data sets. Both are largely dependent on public reporting of dead or distressed manatees, and the numbers of carcasses and rescued manatees represent a minimum count since some carcasses and injured or sick manatees likely go undetected or unreported. Also, carcass recovery and rescue locations do not necessarily represent the actual location of death or injury but instead represent where the carcass (which can float) or distressed manatee (which can swim, in most cases) was found.
Despite these limitations, the scale and scope of FWC's manatee carcass recovery and live rescue program is unique among marine mammal research programs. Data from manatee carcasses and live rescues are undisputed evidence of marine debris impacts and are necessary to monitor threats and aid conservation managers in developing effective species protection strategies.

Through the long-standing manatee necropsy program, we have documented the potential lethality and extent of marine debris ingestion in the Florida manatee, with the majority of fatal cases involving fishery-related gear. Entanglement in fishery-related gear and other marine debris represents over $25 \%$ of all rescue reports. An intense $(24 \mathrm{~h}$ a day, 7 days a week) statewide manatee rescue reporting program has lessened the impact of the entanglement threat through successful interventions. Sometimes cases go undetected and therefore unresolved with appropriate rescue and medical intervention, so the problem may be more prevalent than is currently known. Unfortunately, ingestion of marine debris, particularly monofilament fishing line and hooks, are seldom detected in an individual until it is too late. In this case, when intervention is unlikely, prevention may be the best (or only) way to deal with the problem. Existing strategies include the Monofilament Recovery and Recycling Program (http://mrrp.myfwc. com), derelict trap removal programs (e.g. http:// myfwc.com/fishing/saltwater/trap-debris/) and beach clean-up initiatives (e.g. http://sea2shore.org/h2o/). Nonetheless, understanding the extent and severity of encounters with fishing gear and other marine debris in Florida manatees may be useful for continued refinement of threat analyses (e.g. Runge et al. 2015) and is a needed first step toward development of effective strategies for reducing manatee encounters with fishing gear and other harmful marine debris. Additionally, the persistent and continued observation of active or prior entanglement and the discovery of ingested marine debris during necropsy, and continued reports of live, entangled manatees by the public, indicate that marine debris remains a constant hazard for Florida manatees and, as a 'sentinel' species, for all estuarine fauna and habitats.

Acknowledgements. The authors greatly appreciate the efforts of the following people in assisting with acquiring and searching the numerous rescue and mortality records and documentation necessary to prepare the manuscript: FWRI staff at the Marine Mammal Pathobiology Laboratory, especially K. Arrison, M. de Wit, and D. Szemer; FWRI field staff including P. Cook, C. Hudak, C. Rush, and J. Smith; FWRI volunteers K. Michael and K. O'Donnell; E. Nill (Dol- 
phin Research Center, Marathon, FL); B. Wagoner and staff at SeaWorld Orlando; and M. Walsh (University of Florida). We also thank C. Fonnesbeck and J. Martin for statistical input, and M. de Wit, J. Martin, T. Pitchford, J. Valade, L. Ward-Geiger, and several anonymous reviewers for comments on earlier versions of the manuscript. All activities were conducted under USFWS permit \#MA770191 and federal agreements with the FWC.

\section{LITERATURE CITED}

Adimey NM, Hudak CA, Powell JR, Bassos-Hull K and others (2014) Fishery gear interactions from stranded bottlenose dolphins, Florida manatees and sea turtles in Florida, USA. Mar Pollut Bull 81:103-115

Akaike H (1973) Information theory and an extension of the maximum likelihood principle. In: Petran N, Csaki F (eds) Proc 2nd Int Symp Information Theory. Akademiai Kiado, Budapest, p 267-281

Arthur C, Sutton-Grier AE, Murphy P, Bamford H (2014) Out of sight but not out of mind: harmful effects of derelict traps in selected US coastal waters. Mar Pollut Bull 86: 19-28

Bachteler D, Dehnhardt G (1999) Active touch performance in the Antillean manatee: evidence for a functional differentiation of facial tactile hairs. Zoology 102:61-69

Beck CA, Barros NB (1991) The impact of marine debris on the Florida manatee. Mar Pollut Bull 22:508-510

Beck CA, Lefebvre LW (1995) Are female manatees more vulnerable to entanglement in crab trap lines? Abstract. 11th Biennial Conf Biol Mar Mamm, December 14-18, 1995, Orlando, FL

Bonde RK, Aquirre AA, Powell J (2004) Manatees as sentinels of marine ecosystem health: Are they the 2000pound canaries? EcoHealth 1:255-262

Bonde RK, Garrett A, Berlanger M, Askin N, Tan L, Wittnich C (2012) Biomedical health assessments of the Florida manatee in Crystal River - providing opportunities for training during the capture, handling, and processing of this unique aquatic mammal. J Mar Anim Ecol 5:17-28

Bowles AE, Alves CD, Anderson RC (2001) Manatee behaviors in the presence of simulated fishing gear: response to novelty and the potential for reducing gear interactions. Report by Hubbs-Sea World Research Institute for the US Fish and Wildlife Service on Permit MA0102490. HSWRI Technical Report 2001-317, San Diego, CA

*Bugoni L, Mancini PL, Monteiro DS, Nascimento L, Neves TS (2008) Seabird bycatch in the Brazilian pelagic longline fishery and a review of capture rates in the southwestern Atlantic Ocean. Endang Species Res 5:137-147

Calleson CS (2014) Issues and opportunities associated with using manatee mortality data to evaluate the effectiveness of manatee protection efforts in Florida. Endang Species Res 26:127-136

* Carr A (1987) Impact of non-degradable marine debris on the ecology and survival outlook of sea turtles. Mar Pollut Bull 18:352-356

Caswell H, Brault S, Read AJ, Smith TD (1998) Harbor porpoise and fisheries: an uncertainty analysis of incidental mortality. Ecol Appl 8:1226-1238

Chaloupka M, Parker D, Balazs G (2004) Modelling postrelease mortality of loggerhead sea turtles exposed to the Hawaii-based pelagic longline fishery. Mar Ecol Prog Ser 280:285-293
Crawley MJ (2007) The R book. John Wiley \& Sons, London Deutsch CJ (2008) Trichechus manatus ssp. latirostris. In: IUCN 2012. IUCN Red List of Threatened Species. Version 2012.1. www.iucnredlist.org (accessed 14 October 2012)

Deutsch CJ, Reid J, Bonde R, Easton D, Kochman H, O'Shea $\mathrm{T}$ (2003) Seasonal movements, migratory behavior, and site fidelity of West Indian manatees along the Atlantic coast of the United States. Wildl Monogr 151:1-77

* Donohue MJ, Boland RC, Sramek CM, Antonelis GA (2001) Derelict fishing gear in the Northwestern Hawaiian Islands: diving surveys and debris removal in 1999 confirm threat to coral reef ecosystems. Mar Pollut Bull 42: 1301-1312

Dowdy S, Wearden S (1991) Statistics for research, 2nd edn. John Wiley \& Sons, New York, NY

Forrester DJ, White FH, Woodard JC, Thompson NP (1975) Intussusception in a Florida manatee. J Wildl Dis 11: 566-568

Fry DM, Fefer SI, Sileo L (1987) Ingestion of plastic debris by Laysan albatrosses and wedge-tailed shearwaters in the Hawaiian Islands. Mar Pollut Bull 18:339-343

FWC (Florida Fish and Wildlife Conservation Commission) (2013) Commercial fisheries landings data. http://myfwc. $\mathrm{com} / \mathrm{research} / \mathrm{saltwater/fishstats/commercial-fisheries/}$ landings-in-florida/ (accessed 02 April 2015)

FWC (Florida Fish and Wildlife Conservation Commission) (2014) Manatee mortality statistics. http://myfwc.com/ research/manatee/rescue-mortality-response/mortalitystatistics/ (accessed 31 August 2014)

*Gall SC, Thompson RC (2015) The impact of marine debris on marine life. Mar Pollut Bull 92:170-179

Garrison LP (2007) Interactions between marine mammals and pelagic longline fishing gear in the US Atlantic Ocean between 1992 and 2004. Fish Bull 105:408-417

*Gregory MR (2009) Environmental implications of plastic debris in marine settings-entanglement, ingestion, smothering, hangers-on, hitch-hiking and alien invasions. Philos Trans R Soc Lond B Biol Sci 364:2013-2025

*Harr K, Harvey J, Bonde R, Murphy D and others (2006) Comparison of methods used to diagnose generalized inflammatory disease in manatees (Trichechus manatus latirostris). J Zoo Wildl Med 37:151-159

Hartman DS (1979) Ecology and behavior of the manatee (Trichechus manatus) in Florida. American Society of Mammalogists Special Publication No. 5, Pittsburgh, PA. http://dx.doi.org/10.5962/bhl.title.39474

* Heinsohn GE, Marsh H, Spain AV (1976) Extreme risk of mortality to dugongs (Mammalia: Sirenia) from netting operations. Aust Wildl Res 3:117-121

Hines E, Domning D, Aragones LV, Marmontel M, Mignucci-Giannoni AA, Reynolds JE III (2012) Asian dugongs. In: Hines E, Reynolds J, Mignucci-Giannoni A, Aragones LV, Marmontel M (eds) Sirenian conservation: issues and strategies in developing countries. University Press of Florida, Gainesville, FL, p 58-76

Jacobsen JK, Massey L, Gulland F (2010) Fatal ingestion of floating net debris by two sperm whales (Physeter macrocephalus). Mar Pollut Bull 60:765-767

* Jones MM (1995) Fishing debris in the Australian marine environment. Mar Pollut Bull 30:25-33

Karamanlidis AA, Androukaki E, Adamantopoulou S, Chatzispyrou A and others (2008) Assessing accidental entanglement as a threat to the Mediterranean monk seal Monachus monachus. Endang Species Res 5:205-213 
Laist DW (1987) Overview of the biological effects of lost and discarded plastic debris in the marine environment. Mar Pollut Bull 18:319-326

Laist DW (1997) Impacts of marine debris: entanglement of marine life in marine debris including a comprehensive list of species with entanglement and ingestion records. In: Coe JM, Rogers DB (eds) Marine debris: sources, impacts, and solutions. Springer-Verlag, New York, NY, p 99-139

Lewison RL, Crowder LB (2007) Putting longline bycatch of sea turtles into perspective. Conserv Bio 21:79-86

Macfadyen G, Huntington T, Cappell R (2009) Abandoned, lost or otherwise discarded fishing gear. UNEP Regional Seas Reports and Studies No. 185; FAO Fisheries and Aquaculture Technical Paper, No. 523. UNEP/FAO, Rome

Marmontel M, O'Shea TJ, Kochman HI, Humphrey SR (1996) Age determination in manatees using growthlayer-group counts in bone. Mar Mamm Sci 12:54-88

Marsh H (2000) Evaluating management initiatives aimed at reducing the mortality of dugongs in gill and mesh nets in the Great Barrier Reef World Heritage Area. Mar Mamm Sci 16:684-694

Marshall CD, Huth GD, Edmonds VM, Halin DL, Reep RL (1998) Prehensile use of perioral bristles during feeding and associated behaviors of the Florida manatee (Trichechus manatus latirostris). Mar Mamm Sci 14:274-289

Martin J, Edwards HH, Fonnesbeck CJ, Koslovsky SM, Harmak CW, Dane TM (2015) Combining information for monitoring at large spatial scales: first statewide abundance estimate of the Florida manatee. Biol Conserv 186: 44-51

Noke WD, O'Dell DK (2002) Interactions between the Indian River Lagoon blue crab fishery and the bottlenose dolphin, Tursiops truncatus. Mar Mamm Sci 18:819-832

Ocean Conservancy (2009) A rising tide of ocean debris. International Coastal Cleanup 2009 Report. The Ocean Conservancy, Washington, DC

Read AJ, Drinker P, Northridge S (2006) Bycatch of marine mammals in US and global fisheries. Conserv Bio 20: 163-169

Reep RL, Bonde RK (2006) The Florida manatee: biology and conservation. University of Florida Press, Gainesville, FL

Ribic CA, Sheavly SB, Rugg DJ, Erdmann ES (2010) Trends and drivers of marine debris on the Atlantic coast of the

Editorial responsibility: Rebecca Lewison, San Diego, California, USA
United States 1997-2007. Mar Pollut Bull 60:1231-1242

* Rommel SA, Costidis AM, Pitchford TD, Lightsey JD, Snyder RH, Haubold EM (2007) Forensic methods for characterizing watercraft from watercraft-induced wounds on the Florida manatee (Trichechus manatus latirostris). Mar Mamm Sci 23:110-132

Runge MC, Langtimm CA, Martin J, Fonnesbeck CJ (2015) Status and threats analysis for the Florida manatee (Trichechus manatus latirostris), 2012: US Geological Survey Open-File Report 2015-1083. http://dx.doi.org/ 10.3133/ofr20151083

Smith KN (1997) Summary of manatee fatalities associated with fishing practices or gear 1974-1996. Florida Department of Environmental Protection Resource Management Notes, Spring 1997, Tallahassee, FL. 9(1):9-10

Smith SDA, Edgar RJ (2014) Documenting the density of subtidal marine debris across multiple marine and coastal habitats. PLOS ONE 9:e94593

Sokal RR, Rohlf FJ (1995) Biometry, 3rd edn. W.H. Freeman, New York, NY

* Stewart BS, Yochem PK (1987) Entanglement of pinnipeds in synthetic debris and fishing net and line fragments at San Nicolas and San Miguel islands, California, 19781986. Mar Pollut Bull 18:336-339

*Tasker ML, Camphuysen CJ, Cooper J, Garthe S, Montevecchi WA, Blaber SJM (2000) The impacts of fishing on marine birds. ICES J Mar Sci 57:531-547

*Uhrin AV, Schellinger J (2011) Marine debris impacts to a tidal fringing-marsh in North Carolina. Mar Pollut Bull 62:2605-2610

US Census Bureau (2010) 2010 data. http://www.census.gov/ 2010census/data/ (accessed 10 October 2014)

US Department of the Interior, US Fish and Wildlife Service, US Department of Commerce, US Census Bureau (2014) 2011 National survey of fishing, hunting, and wildlifeassociated recreation. www.census.gov/prod/www/fishing. html

Visit Florida (2014) Fishing hot spots. www.visitflorida. com/en-us/fishing/hotspots.html (accessed 16 October 2014)

Wells RS, Allen JB, Hofmann S, Bassos-Hull K and others (2008) Consequences of injuries on survival and reproduction of common bottlenose dolphins (Tursiops truncatus) along the west coast of Florida. Mar Mamm Sci 24: 774-794

Submitted: January 14, 2016; Accepted: February 13, 2017 Proofs received from author(s): April 24, 2017 